\title{
Retrovirus-mediated gene transfer targeted to retinal photocoagulation sites
}

\author{
T. Murata ${ }^{1}$, S. Hoffmann ${ }^{1}$, T. Ishibashi ${ }^{2}$, C. Spee ${ }^{1}$, E. M. Gordon ${ }^{3}$, W. F. Anderson ${ }^{3}$, D. R. Hinton ${ }^{4}$, S. J. Ryan ${ }^{1}$ \\ ${ }^{1}$ Department of Ophthalmology, Doheny Eye Institute, University of Southern California School of Medicine, Los Angeles, \\ California, USA \\ ${ }^{2}$ Department of Ophthalmology, Faculty of Medicine, Kyushu University, Fukuoka, Japan \\ ${ }^{3}$ Department of Pediatrics and Biochemistry, University of Southern California School of Medicine, Los Angeles, California, USA \\ ${ }^{4}$ Department of Pathology, University of Southern California School of Medicine, Los Angeles, California, USA
}

Summary Diabetic retinopathy is a major cause of acquired blindness due to the development of retinal neovascularization and associated traction retinal detachment. It is commonly treated with retinal photocoagulation therapy; however, progression to blindness remains a significant problem. To determine the feasibility of adjunctive anti-angiogenic gene therapy, we evaluated the capability of retroviral vectors, which transfer exogenous genes only into dividing cells, to transfer and express a $\beta$-galactosidase gene selectively into photocoagulation sites. Thirty-five rabbits received 30 retinal photocoagulation burns in the right eye followed 2 days later by $\beta$-galactosidase $(\mathrm{G} 1 \mathrm{nBgSvNa})$ or control (G1XSvNa) vector injection into the subretinal space. $\beta$-galactosidase expression was observed in the photocoagulation sites from 5 days after vector administration $(31.7 \pm 7.0 \%)$ to 12 weeks $(6.7 \pm 3.4 \%)$. Immunohistochemical studies of the treated retinas using antibody Ber-MAC3 and anti-cytokeratin antibodies revealed that transduced cells were macrophages and retinal pigment epithelial cells. To determine feasibility in a primate, two monkeys received 10 laser burns in the macula superior to the fovea followed 2 days later by $\mathrm{G} 1 \mathrm{nBgSvNa}$ vector. $\beta$-galactosidase expression was found in photocoagulation sites and foveal retina was well preserved. We conclude that gene transfer to retinal photocoagulation sites provides stable expression of the transduced gene with relatively high efficiency. This feasibility study suggests the possibility of transferring genes encoding for anti-angiogenic factors into photocoagulation sites to improve the efficacy of laser photocoagulation therapy. [Diabetologia (1998) 41: 500-506]

Keywords Gene therapy, diabetic retinopathy, photocoagulation, retrovirus, $\beta$-galactosidase.
Diabetic retinopathy is a major cause of acquired blindness and is typically associated with the development of retinal neovascularization in the proliferative stage of the disease. Prevention and/or treatment of non-proliferative diabetic retinopathy (NPDR) by control of blood glucose level is critical; however, once proliferative diabetic retinopathy (PDR) devel-

Received: 26 September 1997 and in revised form: 22 December 1997

Corresponding author: S. J. Ryan, M. D., Doheny Eye Institute, 1450 San Pablo Street, Los Angeles, CA 90033, USA Abbreviations: $\beta$-Gal, $\beta$-galactosidase; NPDR, non proliferative diabetic retinopathy; PDR, proliferative diabetic retinopathy; RPE, retinal pigment epithelial; PBS, phosphate-buffered saline; VEGF, vascular endothelial growth factor. ops, it often progresses rapidly in a manner independent of blood glucose level [1]. The development of PDR has been shown to be associated with the expression of several angiogenic diffusible factors including vascular endothelial growth factor (VEGF) $[2,3]$. One of the approaches that potentially could inhibit the progression of PDR would be the local long-term expression of anti-angiogenic factors in the retina. Gene therapy has the potential to deliver such genes to the retina and has been used to modify the course of other retinal disease such as experimental proliferative vitreoretinopathy [4] and retinal degeneration in the rd mouse [5].

The vector of choice for delivery to the retina depends upon the cells to be targeted and the length of time that expression is required. For diabetic retinopathy, long-term expression must be achieved to ob- 
tain therapeutic benefit since the disorder is chronic in nature. Adenoviral vectors can transfer genes into both quiescent and mitotic retinal cells [5-10]. They have a high gene transfer efficiency; however, the expression of transferred genes is transient, most probably due to an immune response to the virus [11]. Herpes viruses can also be used for gene transfer into ocular tissues $[12,13]$; however, even replication-deficient herpes viruses show evidence of cytotoxicity [14]. Retroviral vectors have been the carrier of choice in the majority of clinical human gene therapy trials because they have been found to be generally safe with no unexpected toxicities described [15]. Exogenous genes are inserted into the host chromosomal DNA of dividing cells resulting in lower gene transfer efficiencies than for adenoviral vectors; however, this integration results in long-term expression of the transduced genes [15]. Because of these features, we concluded retroviral vectors were the vector of choice for delivering anti-angiogenic genes to the diabetic retina. In order to succeed, however, sufficient numbers of proliferating cells had to be obtained. While the proliferating endothelial cells in the retinal neovascularization observed in the PDR were a potential target, this was unlikely to be a viable option since the number of dividing endothelial cells at any one time is relatively small (unpublished data), and access to the cells is limited by fibrous tissue, thick basement membranes and perivascular cells. For this reason, we attempted to induce potential targets for gene therapy by inducing proliferation in the retina by photocoagulation, the most commonly used treatment to inhibit and/or regress retinal neovascularization. Photocoagulation destroys retinal pigment epithelial (RPE) cells and overlying photoreceptor cells and initiates a local wound healing response in which cell proliferation occurs; however, whether this was sufficient to achieve measurable gene transduction in the retina was not known.

The therapeutic effect of photocoagulation is thought to be due to a combination of effects including destruction of angiogenic-factor-producing ischaemic outer retina [1], improved inner retinal oxygenation by removal of metabolically active photoreceptors [16], and stimulation of RPE to produce anti-angiogenic factors [17]. Transduction of genes encoding anti-angiogenic factors into the photocoagulation sites could make photocoagulation more efficacious in inhibiting retinal neovascularization, which is a major risk factor for severe visual loss $[18,19]$. To determine the feasibility of gene therapy to improve the efficacy of photocoagulation therapy for treatment of PDR, we evaluated the capacity of a subretinally injected retroviral vector to transduce the $\beta$-galactosidase $(\beta$-Gal) gene into retinal photocoagulation sites and its subsequent long-term expression.

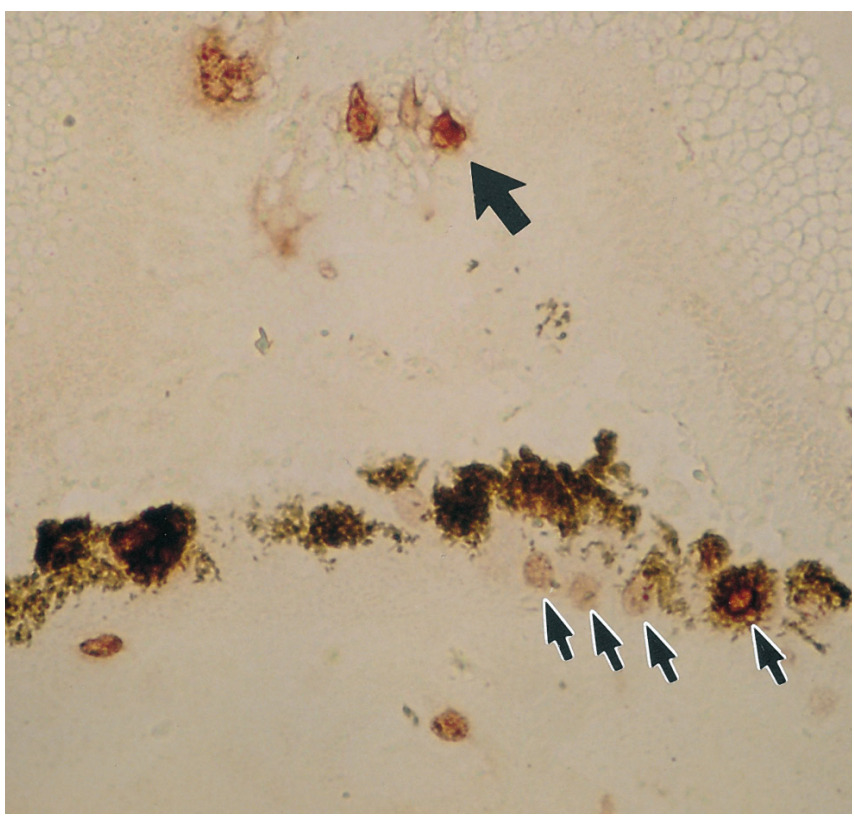

Fig. 1. Immunohistochemistry for Ki-67. Two days after photocoagulation, infiltrating macrophage-like cells (arrow) and retinal pigment epithelium (small black and white arrows) are dividing, $\times 100$

\section{Materials and methods}

Photocoagulation. Forty-three male pigmented rabbits (New Zealand Red) and two cynomolgus monkeys were used in the present study. All procedures were conducted in accordance with the Association of Research in Vision and Ophthalmology Resolution on the Use of Animals in Ophthalmic and Vision Research and were approved by the University of Southern California Institutional care and use committee. The rabbits were aenesthetized with an intramuscular injection of a mixture of ketamine hydrochloride $(24 \mathrm{mg} /$ $\mathrm{kg})$ and xylazine hydrochloride $(5 \mathrm{mg} / \mathrm{kg})$. The monkeys were anaesthetized with a mixture of ketamine hydrochrolide $(24 \mathrm{mg} / \mathrm{kg})$ and acepromazine maleate $(0.005 \mathrm{mg} / \mathrm{kg})$, and $0.03 \mathrm{mg} / \mathrm{kg}$ of atropine sulphate was given intramuscularly. In rabbits, thirty burns of diode laser photocoagulation ( $200 \mu \mathrm{m}$ spot size, $0.2 \mathrm{~s}$ duration, $200 \mathrm{~mW}$ ) were delivered to the retina inferior to the optic disc through a slit-lamp using a contact lens. In monkeys, 10 photocoagulation burns under the same coagulation conditions were delivered in the macular region superior to the fovea, and the eyes were followed by fluorescein angiography after $\beta$-Gal gene transduction.

Retroviral vector. The $\beta$-Gal expression vectors $\mathrm{G} 1 \mathrm{nBgSvNa}$ (G1, MoMuLV LTR; nBg, nuclear targeted $\beta$-Gal gene, Sv, SV40 early region enhancer/promotor; $\mathrm{Na}$, neo ${ }^{\mathrm{r}}$ gene) and G1XSvNa (containing only the SV40 promotor-driven neo ${ }^{r}$ gene) (Genetic Therapy, Inc., Gaithersburg, Md., USA) were concentrated by ultracentrifugation to a titre of $1 \times 10^{8}$ colony forming unit (cfu)/ml after collection in UltraDOMA (Biowhittaker, Walkersville, Md., USA) serum free medium. All producer cell lines tested negative for replication-competent virus.

Immunohistochemistry for Ki-67 in the photocoagulation sites. Two rabbits each per day were killed with an overdose of sodi- 


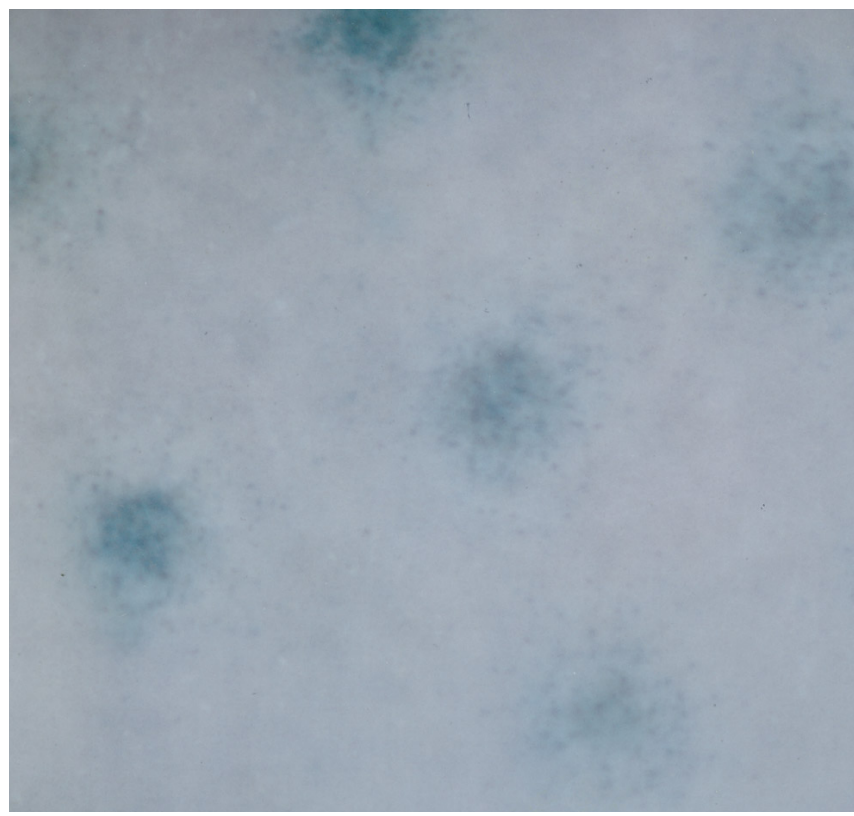

Fig. 2. Exposed fundus of the eye stained with X Gal, observed with a dissecting microscope. The eye received $100 \mu \mathrm{l}$ of $\beta$-galactosidase vector $(\mathrm{G} 1 \mathrm{nBgSvNa})$ supernatant in the subretinal space 2 days after photocoagulation. The laser sites show blue reaction products indicating successful $\beta$-galactosidase transduction and expression

um pentobarbital $(200 \mathrm{mg} / \mathrm{kg})$ on 1, 2, 3 and 5 days after photocoagulation. To find the optimal timing for vector administration, the numbers of the dividing cells in the photocoagulation sites were counted using immunohistochemistry for Ki-67 (MIB5; Immunotech, Westbrook, Me., USA), an antibody that identifies cells in G1, S and G2 phases of the cell cycle. Ten serial sections were cut from each eye in which 9 to 12 photocoagulation sites were identified. The number of Ki-67 positive cells was then counted and identified according to morphologic criteria and in comparison to adjacent sections stained for cytokeratin (Dako, Glostrup, Denmark), which reacts only with RPE cells in the retinochoroidal tissue, or for Ber-MAC3, which is specific for macrophages (Accurate Chemical \& Scientific Co., Westbury, N. Y., USA).

In vivo transduction of $\mathrm{G} \ln \mathrm{BgSvNa}$. Two days after photocoagulation, $100 \mu \mathrm{l}$ of $\mathrm{G} 1 \mathrm{nBgSvNa}$ (30 rabbits and 2 monkeys) or G1XSvNa (5 rabbits) was administered in the right eye of each animal, using an ophthalmic surgical microscope. A glass micropipette with an $80-\mu \mathrm{m}$ tip was introduced through the sclerotomy under visual control and was advanced into the retina. We injected $100 \mu \mathrm{l}$ of vector supernatant into the subretinal space overlying the photocoagulation sites. In rabbits, control eyes $(n=5)$ received G1XSvNa.

Macroscopic observation of $\beta$-Gal expression in the laser coagulation sites. The animals were killed with an overdose of sodium pentobarbital (200 mg/kg). On days 1 and 5, respectively, 1 and 2 rabbits were killed. At 1, 2, 4, 8, and 12 weeks, respectively, $6,11,9,3$, and 3 rabbits were killed. One monkey was killed at 2 weeks and the other at 8 weeks. Twenty-nine of 35 rabbit eyes as well as 2 monkey eyes used for experiments were placed directly into $0.2 \%$ glutaraldehyde and $2 \%$ paraformaldehyde in $0.1 \mathrm{~mol} / 1$ phosphate-buffered saline (PBS, pH 7.4) immediately after enucleation. The residual 6

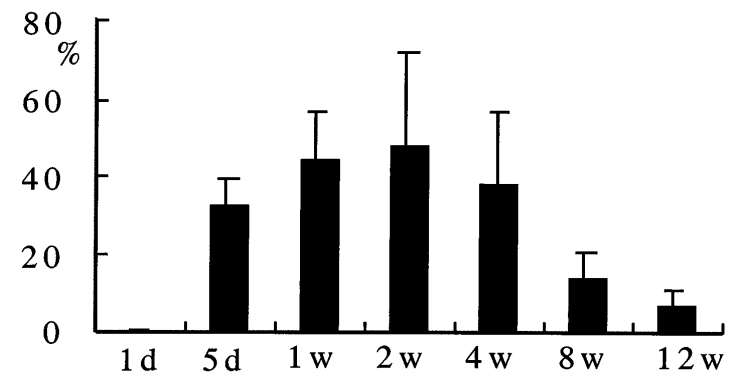

Fig. 3. The time course of $\beta$-galactosidase expression in the photocoagulation sites. $\beta$-galactosidase expression was observed in $0 \%$ (day 1), $31.7 \pm 7.0 \%$ (day 5 ), $43.4 \pm 13.0 \%$ ( 1 week $), 47.0 \pm 24.1 \%$ (2 weeks), $37.7 \pm 18.1 \%$ (4 weeks), $13.3 \pm 6.7 \%$ ( 8 weeks $)$ and $6.7 \pm 3.4 \%$ (12 weeks $)$ of the photocoagulation sites. d: $\operatorname{day}(\mathrm{s})$, w: week(s)

rabbits' eyes ( 3 each at 2 and 4 weeks) were fixed with $4 \%$ paraformaldehyde for immunohistochemistry. X-gal staining was performed as previously described [4]. Using a dissecting microscope, the retinas were examined and the number of photocoagulation sites with or without $\beta$-Gal expression was counted.

Histopathologic analysis. In rabbits, 1 eye each from days 1 and 5 , and 2, 4, 5, 2 and 2 eyes from weeks 1,2, 4, 8, 12, respectively, were used for histopathologic examination. Two eyes, one from each monkey, were also fixed for histopathologic examination. The sections were examined by light microscopy to confirm the nuclear $\beta$-Gal expression. To identify the cell types transduced with $\beta$-Gal, immunohistochemistry for cytokeratin and for Ber-MAC3 was performed on $\beta$-Gal reacted slides in 3 eyes each from 2 and 4 weeks.

The dissected macular regions in the monkey eyes were dehydrated in a series of graded alcohols and embedded in glycol methacrylate. Two to three micrometre sections were stained with periodic acid-Schiff.

\section{Results}

Immunohistochemistry for Ki-67 in the photocoagulation sites. One day after photocoagulation, there were no Ki-67 positive cells in the RPE layer. Ki-67 positive macrophage-like cells were observed mainly in the choroid underlying the photocoagulation sites. The number of Ki-67 positive macrophage-like cells in the retina was small (1.8 \pm 1.9 per burn). Two days after photocoagulation (Fig. 1), Ki-67 positive RPE were observed in the photocoagulation sites (4.6 \pm 2.6 per burn). Macrophage-like cells were observed in the subretinal space and within the retina (7.4 \pm 4.1 per burn). Three and five days after photocoagulation, the numbers of Ki-67 positive RPE cells (3.8 \pm 1.8 and $1.4 \pm 1.6$ per burn on 3 and 5 days after photocoagulation, respectively) and macrophagelike cells $(11.4 \pm 6.5$ and $8.6 \pm 7.4$ per burn on 3 and 5 days after photocoagulation, respectively) in the retina remained largely at the same level. Thus, 2 days after photocoagulation appeared to be the op- 

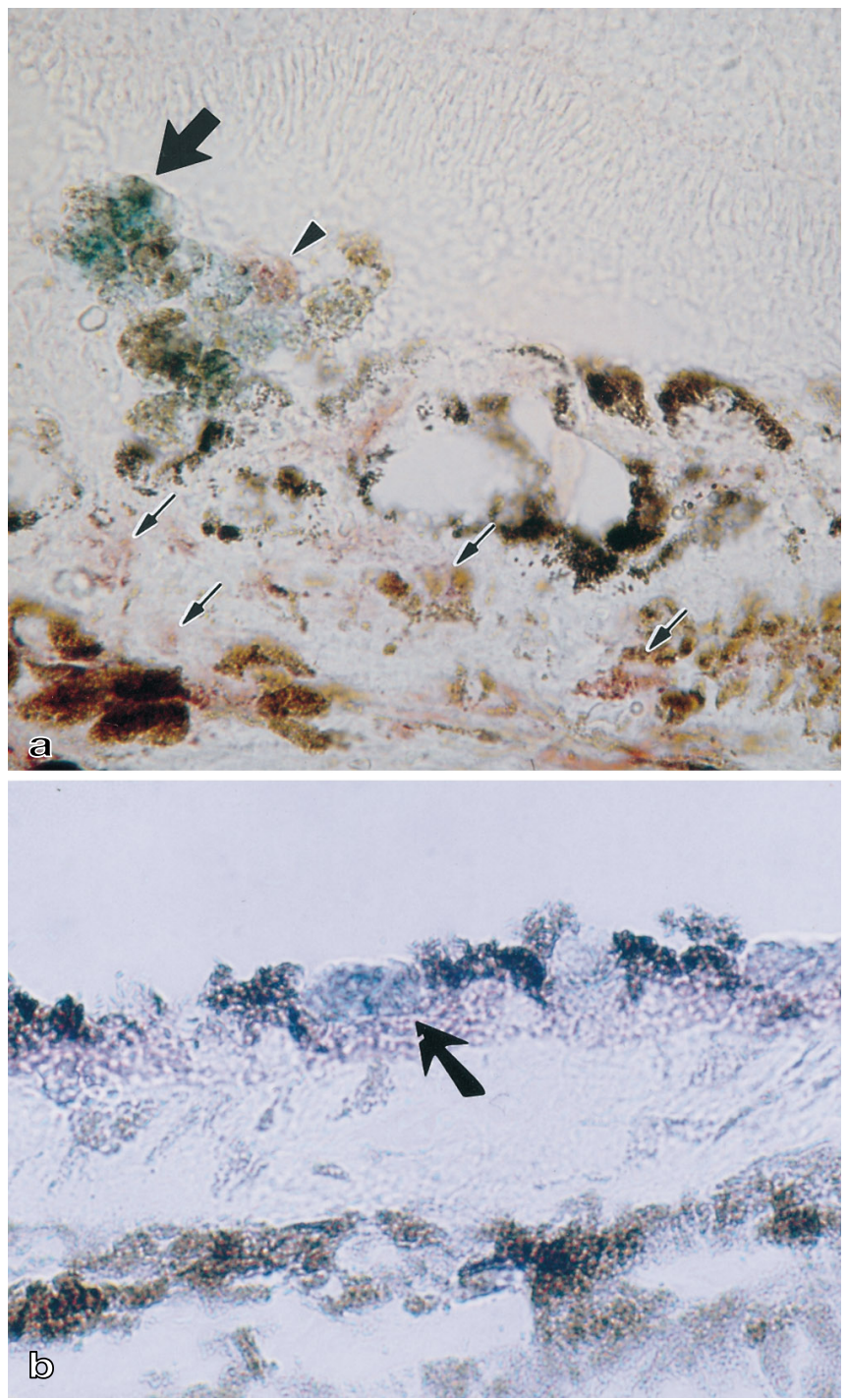

Fig.4. a) Double staining for $\beta$-galactosidase (blue reaction product) and macrophage marker (Ber-MAC3; red reaction product) at 4 weeks. Macrophage-like cells expressing $\beta$-Gal are located in subretinal space (arrow) and some of them show positive reaction for macrophage marker (arrowhead). Macrophages are also seen in the choroid (small arrows), magnification $100 \times$. b) Double staining for $\beta$-galactosidase (blue reaction product) and a marker of retinal pigment epithelial (RPE) cells (cytokeratin; red reaction product) at the edge of the photocoagulation sites, at 4 weeks. Adjacent RPE cells are positive for $\beta$-galactosidase (arrow), magnification $100 \times$

timal time for vector supernatant administration in the subretinal space.

Macroscopic observation of $\beta$-Gal expression in the photocoagulation sites in rabbit eyes. Blue positive reaction products were seen exclusively in the photocoagulation sites indicating $\beta$-Gal transduction and expression (Fig. 2). In other regions of the experimental eyes or in the entire control eyes, no blue reaction product was observed. The time course of $\beta$-Gal ex- pression in the photocoagulation sites is summarized in Figure 3. $\beta$-Gal expression was first observed on day $5(31.7 \pm 7.0 \%)$, highest levels were seen at 2 weeks $(43.3 \pm 13.0 \%)$ and expression was observed for as long as 12 weeks $(6.7 \pm 3.4 \%)$.

Histopathologic analysis in rabbit eyes. One day after subretinal injection of vector supernatant, the photoreceptors over the photocoagulation sites showed degenerative changes. The inner layers of the retinas from the outer plexiform layer to the inner limiting membrane were well preserved. Inflammatory response in the retina was minimal. There were no $\beta$ Gal positive cells seen. On day 5 and at 2 weeks, melanin-laden macrophage-like cells were observed in all layers of the retina. From 4 weeks to 12 weeks, macrophage-like cells decreased in number and were observed mainly in the deeper layers of the retinas. From day 5 to 12 weeks, these macrophage-like cells expressed $\beta$-Gal. Immunohistochemistry for macrophages revealed positive reaction with some of these cells (Fig. 4 a). At the edge of photocoagulation sites, RPE cells expressing $\beta$-Gal were also observed from day 5 to 12 weeks (Fig. 4 b).

Fluorescein angiography and histopathologic examination in monkey eyes. Except for a mild window defect caused by the G1nBgSvNa supernatant injection, no abnormal findings such as macular oedema or fluorescein leakage from the retinal vessels were observed in the fluorescein angiogram (Fig. 5 a). Light microscopic examination revealed excellent preservation of the retina in the fovea, without retinal degeneration or inflammatory cell infiltration (Fig. 5b). In the photocoagulation sites, $\beta$-Gal positive macrophages and RPE cells were present though they were fewer in number than in comparable rabbit photocoagulation sites. These findings indicate that exogenous gene delivery performed in this experiment did not affect the fovea of the retina, which is important for central vision.

\section{Discussion}

Retroviral vectors have been the most commonly used vectors in clinical gene therapy trials, and have been found to be generally safe with no unexpected toxicities described [15]. Retroviral vectors insert exogenous genes into host chromosomes and provide long-term expression [15, 20, 21], which is indispensable to obtain a therapeutic effect for chronic diseases such as diabetic retinopathy. Formerly, this characteristic was considered problematic as well, because retroviral vectors insert genes randomly, instead of into predictable sites. Depending on where inserted, the genes could potentially disrupt an essential gene, resulting in disease, or alter genes in ways that favour 

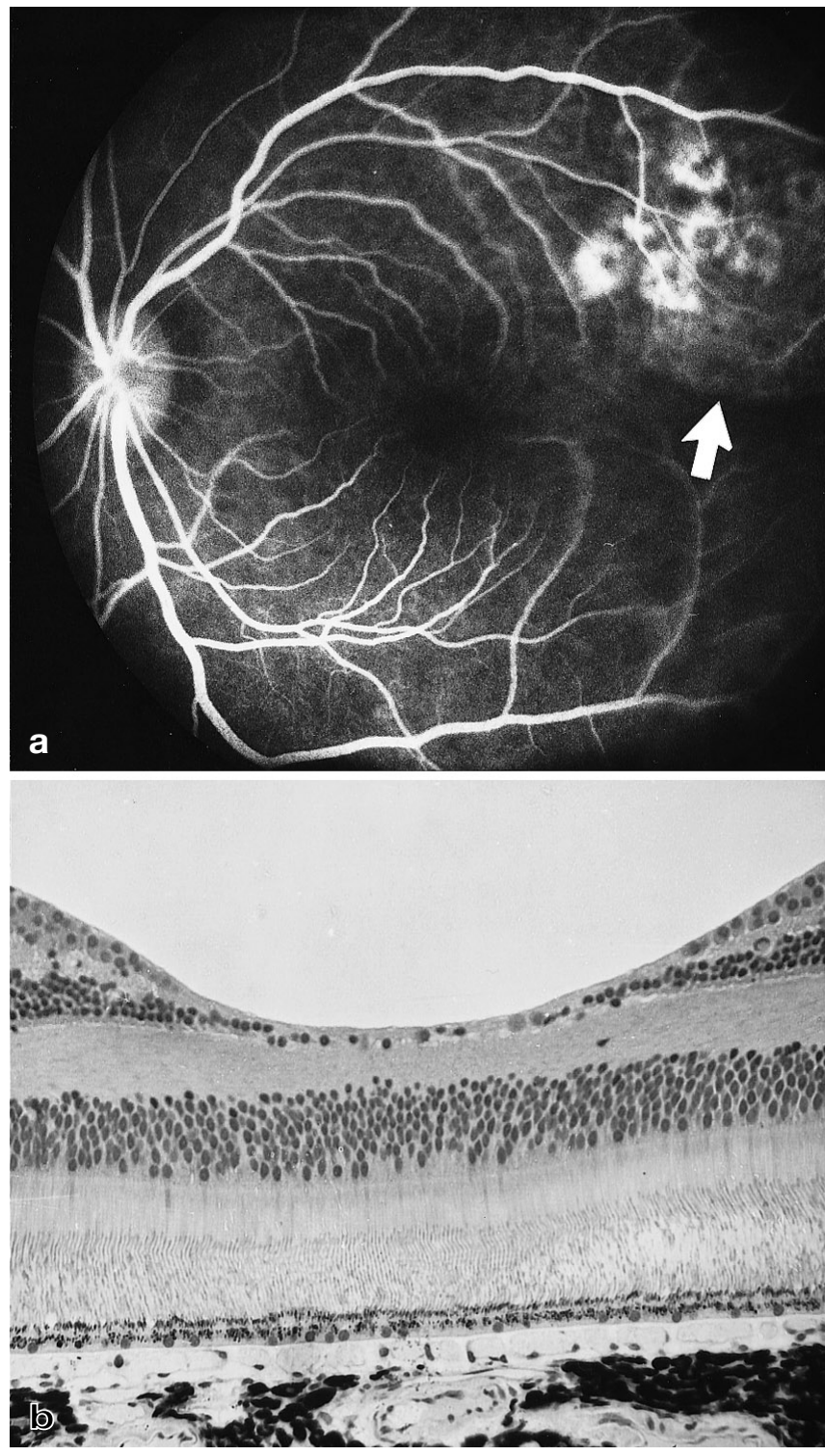

Fig.5. a) Fluorescein angiogram of the eye which underwent photocoagulation and $\beta$-galactosidase vector $(\mathrm{G} 1 \mathrm{nBgSvNa})$ supernatant administration at 8 weeks. Mild window defect caused by supernatant injection is observed (arrows). There is no other apparent abnormal finding, indicating gene transfer did affect the fovea which is important for central vision. b) Light micrograph of the eye shown in a). Retinal architecture at the fovea is well preserved. Neither retinal degeneration nor inflammatory cell infiltration is observed (Periodic acid-Schiff, magnification $250 \times$ )

tumour development; however, the potential risk of unwanted side effects caused by promiscuous gene transfer has been proven negligible [15, 20,21].

The efficacy of retroviral transduction should be improved if the vector is targeted specifically to the cells of interest. This can be achieved in part by local administration of the vector by isolated-organ perfusion [22] or into a confined organ such as the eye [4]. Vector-specific modification includes altering the vectors so that they show increased affinity for sur- face molecules on the targeted cells [20, 21, 23], or transcriptional targeting in which genes are delivered under the control of appropriate cell-specific promotors [21, 24].

In the present study, we demonstrated a method of targeted gene transfer into photocoagulation sites by subretinal injection of supernatant containing a $\beta$ $\mathrm{Gal}$ retroviral vector, G1nBgSvNa. Since retroviral vectors transduce exogenous genes only into dividing cells, and the normal adult retina does not include proliferating cells, the gene transfer was targeted selectively to the photocoagulation sites. By macroscopic observation, $\beta$-Gal expression was first observed 5 days after $\mathrm{G} 1 \mathrm{nBgSvNa}$ administration. The ratio of the number of photocoagulation sites that expressed $\beta$-Gal was highest at 2 weeks $(43.3 \pm 13.0 \%)$ and was observed up to 12 weeks $(6.7 \pm 3.4 \%)$.

In vivo transduction efficiency of retroviral vectors is generally low $[15,20,21]$. Injection of the same vector supernatant at lower titre $\left(1 \times 10^{6} \mathrm{cfu} / \mathrm{ml}\right)$ with cultured fibroblasts into the vitreous cavity resulted in $2 \%$ transduction efficiency of $\beta$-Gal into the fibroblasts [4]. We suggest that the relatively high transduction efficiency observed in the present study could be attributed to the use of $\mathrm{G} 1 \mathrm{nBgSvNa}$ vector at a higher titre $\left(1 \times 10^{8} \mathrm{cfu} / \mathrm{ml}\right)$, and to the direct injection of vector supernatant into the subretinal space thus limiting dilution. Intravitreal injection of the vector supernatant was also tried, but there were no transduced cells observed, probably because the vector did not penetrate the retina to access the photocoagulation sites (data not shown). Vectors may also have been diluted in the relatively large vitreous volume, or transduction may have been inhibited by vitreous fluid [4]. Immunohistochemical examination revealed that the cells transduced with $\beta$-Gal in photocoagulation sites were RPE cells and macrophages, the same cell types found to be proliferating using $\mathrm{Ki}$ 67 antibody. Fluid flow from retina to choroid should increase interaction between $\mathrm{G} 1 \mathrm{nBgSvNa}$ vector and RPE. It has been well established that there is a fluid flow from the centre of the eye, across the retina towards the choroid [25]. Directed vector motion to targeted cells by fluid flow has been demonstrated to increase the rate of gene transfer [26]. The phagocytic activity of both macrophages and RPE might also have increased the amount of transduction with G1nBgSvNa vector.

In the present study, the number of photocoagulation sites expressing $\beta$-Gal decreased at a later stage, probably due to the clearance of transduced macrophages from the photocoagulation sites. On the other hand, $\beta$-Gal expressing RPE cells remained at the photocoagulation sites and kept expressing the transduced exogenous genes. Thus $\beta$-Gal expression was confirmed in $6.6 \pm 3.4 \%$ of the photocoagulation sites even at 12 weeks after $\mathrm{G} 1 \mathrm{nBgSvNa}$ administration. 
One potential strategy to make photocoagulation more efficacious in inhibiting retinal neovascularization is to transduce genes encoding anti-angiogenic factors in the photocoagulation sites. Since the photocoagulation sites are located in the subretinal space and the neovascularization in diabetic retinopathy occurs in the inner retina, a distance of about $200 \mu \mathrm{m}$ in the human, genes that encode diffusible anti-angiogenic factors should be used. In support of this approach, analysis of the distribution kinetics of macromolecules injected into the subretinal space revealed that macromolecules were cleared mainly through the retina and the vitreous cavity rather than the choroid [27]. Gene transfer of thrombospondin-1 [28], flk-1 dominant negative mutant [29], or platelet factor 4 [30] have been reported to be effective in inhibiting tumour angiogenesis. Tissue inhibitors of metalloproteinases [31, 32] and antisense against VEGF [33] are other potential candidates to use in this strategy. Since VEGF is known to induce not only retinal neovascularization [3] but also retinal oedema [2], which is also a major risk factor of visual loss, antisense against VEGF would be an especially promising agent.

Most of the $\beta$-Gal expressing RPE cells were single cells; however, there were also $\beta$-Gal expressing RPE cells which were located in clusters or in a row (data not shown). We suggest that this distribution of RPE was due to cell division of one transduced RPE with $\beta$-Gal. At the edge of photocoagulation sites, RPE regenerate and migrate to cover the burns [34]. As the transduced RPE cells divide, the progeny also express the $\beta$-Gal gene resulting in clusters of $\beta$ Gal-expressing RPE cells in a row.

The feasibility of exogenous gene transfer into photocoagulation sites was also confirmed in primate eyes when vector supernatant was administered in the macular region. Fluorescein angiography revealed no abnormal findings such as macular oedema or the leakage from the vessels. In histologic examination, the structure of the foveal region was well preserved and there was no evidence of an inflammatory response.

The present study indicates that an exogenous gene can be transduced exclusively into photocoagulation sites with relatively high transduction efficiency, and that the encoded protein can be expressed for at least 12 weeks. There was no apparent adverse effect on the foveal region that is essential for central vision. These results suggest that if genes that encode diffusible anti-angiogenic factors can be transduced using a retroviral vector, they would be expressed at photocoagulation sites in a stable manner. The expressed anti-angiogenic factors could reach the inner retina where neovascularization is located. Inhibition of retinal neovascularization by this method might lead to a better control of diabetic retinopathy and reduction of the incidence of visual disturbance caused by this disease. In addition, since gene transduction occurs exclusively in the photocoagulation sites, the potential risk of side effects caused by unwanted gene transfer into other regions necessary for vision could be reduced.

Acknowledgements. Supported in part by grants EY01545 and EY03040 from National Institute of Health and by The Hoover Foundation. The Department of Ophthalmology is a recipient of an unrestricted award from Research to Prevent Blindness, Inc., New York, New York. The authors are grateful to Dr. Thomas E. Ogden for his expertise.

\section{Reference}

1. Davis MD (1994) Proliferative diabetic retinopathy. In: Ryan SJ (ed) Retina. 2nd ed. Vol 2. Mosby, St. Louis, pp1319-1359

2. Murata T, Nakagawa K, Khalil A, Ishibashi T, Inomata $H$, Sueishi K (1996) The relation between expression of vascular endothelial growth factor and breakdown of the bloodretinal barrier in diabetic rat retinas. Lab Invest 74: 819-825

3. Aiello LP, Pierce EA, Foley ED et al. (1995) Suppression of retinal neovascularization in vivo by inhibition of vascular endothelial growth factor (VEGF) using soluble VEGF-receptor chimeric proteins. Proc Natl Acad Sci U S A 92: 10457-10461

4. Kimura H, Sakamoto T, Cardillo JA et al. (1996) Retrovirus-mediated suicide gene transduction in the vitreous cavity of the eye: feasibility in prevention of proliferative vitreoretinopathy. Hum Gene Ther 7: 799-808

5. Bennett J, Tanabe T, Sun D et al. (1996) Photoreceptor cell rescue in retinal degeneration (rd) mice by in vivo gene therapy. Nat Med 2: 649-654

6. da Cruz L, Rakoczy P, Perricaudet M, Constable IJ (1996) Dynamics of gene transfer to retinal pigment epithelium. Invest Ophthalmol Vis Sci 37: 2447-2454

7. Li T, Adamian M, Roof DJ et al. (1994) In vivo transfer of a reporter gene to the retina mediated by an adenoviral vector. Invest Ophthalmol Vis Sci 35: 2543-2549

8. Bennett J, Wilson J, Sun D, Forbes B, Maguire A (1994) Adenovirus vector-mediated in vivo gene transfer into adult murine retina. Invest Ophthalmol Vis Sci 35: 2535-2542

9. Jomary C, Piper TA, Dickson G et al. (1994) Adenovirusmediated gene transfer to murine retinal cells in vitro and in vivo. FEBS Lett 347: 117-122

10. Cayouette M, Gravel C (1996) Adenovirus-mediated gene transfer to retinal ganglion cells. Invest Ophthalmol Vis Sci 37: 2022-2028

11. Wood MJ, Charlton HM, Wood KJ, Kajiwara K, Byrnes AP (1996) Immune responses to adenovirus vectors in the nervous system. Trends Neurosci 19: 497-501

12. Pepose JS, Leib DA (1994) Herpes simplex viral vectors for therapeutic gene delivery to ocular tissues. Recent breakthroughs in the molecular genetics of ocular diseases. Invest Ophthalmol Vis Sci 35: 2662-2666

13. Breakefield XO, DeLuca NA (1991) Herpes simplex virus for gene delivery to neurons. New Biol 3: 203-218

14. Johnson PA, Miyanohara A, Levine F, Cahill T, Friedmann T (1992) Cytotoxicity of a replication-defective mutant of herpes simplex virus type 1. J Virol 66: 2952-2965 
15. Gunzburg WH, Salmons B (1996) Development of retroviral vectors as safe, targeted gene delivery systems. J Mol Med 74: 171-182

16. Weiter JJ, Zuckerman R (1980) The influence of the photoreceptor-RPE complex on the inner retina. An explanation for the beneficial effects of photocoagulation. Ophthalmology 87: 1133-1139

17. Glaser BM, Campochiaro PA, Davis JJ, Sato M (1985) Retinal pigment epithelial cells release an inhibitor of neovascularization. Arch Ophthalmol 103: 1870-1875

18. The Diabetic Retinopathy Study Research Group (1978) Photocoagulation treatment of proliferative diabetic retinopathy: the second report of diabetic retinopathy study findings. Ophthalmology 85: 82-106

19. The Diabetic Retinopathy Study Research Group (1979) Four risk factors for severe visual loss in diabetic retinopathy. The third report from the Diabetic Retinopathy Study. Arch Ophthalmol 97: 654-655

20. Friedmann T (1997) Overcoming the obstacles to gene therapy. Sci Am 276: 96-101

21. Harris JD, Lemoine NR (1996) Strategies for targeted gene therapy. Trends Genet 12: 400-405

22. de Roos WK, Fallaux FJ, Marinelli AW et al. (1997) Isolated-organ perfusion for local gene delivery: efficient aden5ovirus- mediated gene transfer into the liver. Gene Ther 4: 55-62

23. Schwarzenberger P, Spence SE, Gooya JM et al. (1996) Targeted gene transfer to human hematopoietic progenitor cell lines through the c-kit receptor. Blood 87: 472-478

24. Kido M, Rich KA, Yang G et al. (1996) Use of a retroviral vector with an internal opsin promoter to direct gene expression to retinal photoreceptor cells. Curr Eye Res 15: 833-844

25. Negi A, Marmor MF (1983) The resorption of subretinal fluid after diffuse damage to the retinal pigment epithelium. Invest Ophthalmol Vis Sci 24: 1475-1579
26. Palsson B, Andreadis S (1997) The physico-chemical factors that govern retrovirus-mediated gene transfer. Exp Hematol 25: 94-102

27. Marmor MF, Negi A, Maurice DM (1985) Kinetics of macromolecules injected into the subretinal space. Exp Eye Res 40: 687-696

28. Weinstat SD, Zabrenetzky VS, VanHoutte K, Frazier WA, Roberts DD, Steeg PS (1994) Transfection of thrombospondin 1 complementary DNA into a human breast carcinoma cell line reduces primary tumor growth, metastatic potential, and angiogenesis. Cancer Res 54: 6504-6511

29. Millauer B, Longhi MP, Plate KH et al. (1996) Dominantnegative inhibition of Flk-1 suppresses the growth of many tumor types in vivo. Cancer Res 56: 1615-1620

30. Tanaka T, Manome Y, Wen P, Kufe DW, Fine HA (1997) Viral vector-mediated transduction of a modified platelet factor 4 cDNA inhibits angiogenesis and tumor growth. Nat Med 3: 437-442

31. Benelli R, Adatia R, Ensoli B, Stetler SW, Santi L, Albini A (1994) Inhibition of AIDS-Kaposi's sarcoma cell induced endothelial cell invasion by TIMP-2 and a synthetic peptide from the metalloproteinase propeptide: implications for an anti-angiogenic therapy. Oncol Res 6: 251-257

32. Anand-Apte B, Pepper MS, Voest E et al. (1997) Inhibition of angiogenesis by tissue inhibitor of metalloproteinase-3. Invest Ophthalmol Vis Sci 38: 817-823

33. Robinson GS, Pierce EA, Rook SL, Foley E, Webb R, Smith LE (1996) Oligodeoxynucleotides inhibit retinal neovascularization in a murine model of proliferative retinopathy. Proc Natl Acad Sci U S A 93: 4851-4856

34. Pollack A, Korte GE (1990) Repair of retinal pigment epithelium and its relationship with capillary endothelium after krypton laser photocoagulation. Invest Ophthalmol Vis Sci 31: 890-898 